\title{
Neurodevelopmental Pathways of Childhood ADHD into Adulthood: Maturational Lag, Deviation, or Both?
}

\author{
Alban Burke and Amanda Edge \\ Additional information is available at the end of the chapter \\ http://dx.doi.org/10.5772/53865
}

\section{Introduction}

The DSM-5 [1], which should be published in 2013, will in all likelihood have a category named Neurodevelopmental Disorders, under which ADHD will resort. This shift in nosology lays the foundation of the argument that will be put forward in this chapter, therefore the following points need to be emphasised and warrants further discussion. Firstly, this categorisation is based on shared aetiology, rather than shared symptoms or shared developmental stage (as was the case with the DSM-IV-TR). Historically, disorders were classified according to shared aetiology (as was the case with DSMI and DSM-II), as opposed to shared symptomatology (as was the case with DSM-III and DSM-IVTR). The DSM-5 is to a greater, or lesser, extent a combination of these as it proposes a change to the categorisation, but not the symptoms of this disorder.

The second point is that the shared aetiology is a neurobiological based aetiology. The name of the category implies that these disorders have a common, underlying, neurobiological cause. The question which arises is to what extent these disorders do have an underlying neurobiological cause, to what extent this is shared, and even to what extent these causes are shared within the sub-categories of disorders, for example ADHD. Grouping these disorders together implies a relatively homogenous group of disorders, and even further that the subcategories are homogenous within themselves. The DSM- 5 makes provision for 4 sub-categories of ADHD, i.e. the Combined, Predominantly Inattentive, Inattentive (Restrictive) and predominantly Hyperactivel Impulsive, presentations. Does the grouping of these sub-categories necessarily imply that they share the same neurobiological aetiology? The argument that will be put forward in this chapter is that although they all share a neurobiological cause, this cause is not common and that the sub- categories may have subtle or gross, differences in these neurobiological factors. 
The name of the category also implies a more fluid and dynamic process that starts in childhood and may, or may not, extend across the lifespan into adulthood. This is in sharp contrast to the more traditional, and rather rigid, distinction between adulthood and childhood pathologies. This category allows for the straddling between childhood and adulthood pathologies. An important point, which warrants emphasis, is that these disorders typically originate in childhood, which may then extend into adulthood. Again, in sharp contrast to the previous DSM classifications, the DSM- 5 makes slightly more provision for ADHD in adulthood. As far as the specific criteria, as well as the sub-categories, are concerned, the criteria for ADHD in adulthood are rather superficial as it does not include the rather extensive research that has been done on the clinical manifestation of this disorder in adulthood, nor is it explicit enough in terms of possible sub-categories of this disorder in adulthood. This creates a picture of a rather homogenous disorder in adulthood which either influences, or is perpetuated by, research on this topic.

As much as many Mental Health professionals would like to accept that the diagnosis of ADHD in adulthood is a valid one, there is also still much scepticism about both the validity of this disorder, as well as the clinical picture / diagnostic criteria. Some authors [2] postulate that this scepticism may also be due to extensive, but poorly described, comorbid Axis I and Axis II disorders. Although some may consider ADHD and Personality Disorders (specifically Cluster B) to be co-morbid conditions, there are also those that would argue that these Personality Disorders are often misdiagnosed as ADHD, or vice versa [3]. The roots of the dilemma are twofold, i.e. that Personality Disorders are a separate and distinct set of disorders that do not have a biological underpinning and the arbitrary distinction between childhood and adult pathology. If one removes both these problematic issues, and rather view a disorder in terms of the aberrant development of behaviour, (neuro)cognition and emotion (as opposed to "personality") over time (rather than in life stages), a different picture, i.e. one of either maturational lag or maturational deviance, emerges. The neurodevelopmental disorders, such as ADHD, are associated with a unique temperament that is characterised by high novelty seeking, harm avoidance and low reward dependence [3]. The question that arises is whether the neurodevelopmental and personality disorders are the result of the same underlying neurological process, or whether they are parallel processes that may or may not have reciprocal effects on each other [4]. On a theoretical level, i.e. the maturational lag theory, these two categories of disorders may be considered together, if it is indeed that the maturational lag theory holds true for both of them.

\section{Neurodevelopment of ADHD}

The use of the concept neurodevelopment in the categorisation and organisation of disorders in the DSM-5 suggests that variant disorders can be arranged according to specific neurodevelopmental pathways. It is understood that the developmental pathway may account for the neurobiological underpinnings, and thus aetiological foundation of the syndrome observed. Two neurodevelopmental models, namely the maturational lag model and the develop- 
mental deviation model, appear to be particularly relevant to the syndrome of ADHD. In this section evidence supporting these two views will be reported.

\subsection{Maturational lag in ADHD}

While some evidence has suggested that the ADHD brain develops in fundamentally different ways to typical ones, other results have argued that they are just the result of a lag in the normal timetable for development, which is known as the maturational lag model [5]. This model of ADHD is organised around the notion that that the behaviours of a child with ADHD is abnormal merely in reference to his or her age [5]. This direction in thinking was initially based on observations that children with ADHD behave similarly to younger children who are more active, impulsive and exhibit a shorter attention span [6]. According to this model [5], "if the child was younger, the findings would be regarded as normal" (p. 268). He further postulates that the neurological factors that limit the performance of a child with ADHD are synonymous to that which typically limits the performance of younger children. Hence, the maturational lag model [5] stipulates that an individual with ADHD presents with a relative delay in certain aspects of their neurological maturation, but that maturation will eventually 'catch up'. On average, the brain of ADHD children matured about three years later than those of their peers, with $50 \%$ of their cortex only reaching maximum thickness at age 10 years 6 months as opposed to 7 years and 6 months of those children without ADHD [7]. The lags in maturation seem to differ from one cortical area to the next, for example, the lag in the prefrontal cortex can be as high as 5 years. In other areas, the ADHD brain seems to mature faster than in a non-ADHD brain, an example being the primary motor cortex. These researchers draw the conclusion that their findings support the hypothesis of maturational lag, not maturational deviance.

Nearly 50 years of electrophysiological (EEG) research in the realm of ADHD suggest that children and adolescents who present with the disorder display abnormalities in their EEG [8]. The abnormalities observed are either organised according to the maturational lag or developmental deviation model. From an EEG perspective, the maturational lag model suggests that an individual with ADHD should present with cortical activity that is similar to that witnessed in younger children $[9,10]$, since an increase in slow wave activity (delta and theta) and decreased fast wave activity (alpha and beta) is typical in younger children [11]. A number of researchers [12-16] interpret their findings of increased slow wave activity in children and adolescents with ADHD during an eyes closed resting condition as evidence of a maturational lag. Additional EEG support for the maturational lag is presented in Table 1.

\subsection{Maturational deviance in ADHD}

The second neurodevelopmental model is that of the developmental deviation, also known as maturational deviance, which proposes that maturation is not necessarily lagging, but that it is not approaching normality or maturation, and that it is unlikely to do so at any stage during the lifespan. This model was built on EEG research where $90 \%$ of the ADHD sample presented with aberrances in their EEG activity [17]. Subsequently, the developmental deviation model of ADHD came into play, which suggests that ADHD results from ab- 
normalities in CNS functioning [9]. It further denotes that the EEGs of children and adolescents with ADHD symptoms are not considered normal in children of any age and that it is also not likely to mature in a normal fashion [9]. Additional evidence for this model is provided by the adult ADHD (ADHD) studies which found that the presence of elevated slow wave activity, especially theta, persists into adulthood [18-19].

\subsection{Summary and conclusion}

The research referred to in this section was concerned with the investigation of cortical activity patterns in adults with ADHD via EEG methodologies. The research was specifically interested in the cortical activity patterns of adults with ADHD symptomatology at frontal, frontal midline and parietal sites seeing that these areas are often the most heavily implicated in ADHD. From existing literature, it can be concluded that there is evidence that supports both the maturational lag as well as the maturational deviance models (See Table 1).

\begin{tabular}{|c|c|c|c|}
\hline $\begin{array}{l}\text { EEG Based } \\
\text { Model }\end{array}$ & Description of Model & EEG Findings & References \\
\hline Maturational Lag & $\begin{array}{l}\text { Individuals with ADHD symptoms } \\
\text { present with cortical activity } \\
\text { patterns that is similar to that } \\
\text { witnessed in younger children }\end{array}$ & $\begin{array}{l}\text { Increased relative and/or absolute slow wave activity } \\
\text { and decreased relative and/or absolute fast wave } \\
\text { activity } \\
\text { Increased frontal relative and/or absolute theta } \\
\text { Increased absolute and/or relative delta in temporal } \\
\text { and parietal sites } \\
\text { Decreased relative and/or absolute alpha and beta } \\
\text { power in temporal and parietal sites }\end{array}$ & {$[8-16,20-27]$} \\
\hline $\begin{array}{l}\text { Developmental } \\
\text { Deviation }\end{array}$ & $\begin{array}{l}\text { ADHD symptoms result from } \\
\text { abnormalities in CNS functioning. } \\
\text { The EEGs of individuals with ADHD } \\
\text { symptoms are not considered } \\
\text { normal in individuals of any age and } \\
\text { is not likely to mature in a normal } \\
\text { fashion. }\end{array}$ & $\begin{array}{l}\text { Increased absolute and/or relative theta activity in } \\
\text { frontal and frontal midline sites. } \\
\text { Decreased relative alpha activity in parietal and } \\
\text { temporal sites. } \\
\text { Decreased absolute and relative beta activity in frontal, } \\
\text { parietal and temporal sites } \\
\text { Elevated theta/beta and theta/alpha ratios }\end{array}$ & $\begin{array}{l}{[9,19,26,28,} \\
29]\end{array}$ \\
\hline
\end{tabular}

Table 1. EEG support for the maturational lag and developmental deviation models

\section{Personality disorders}

Personality and psychopathology have, throughout the $20^{\text {th }}$ century, been viewed as separate but related domains. Although they have been viewed as related domains, the exact relationship remains largely unclear. In 1980, within psychopathology, clinical syndromes were separated from personality disorders [34]. Splitting these domains highlighted the overlap between symptoms of clinical and personality disorders [34], which 
is also the foundation for on-going debates concerning the comorbidity between ADHD in adulthood and personality disorders. If one adopts a neurobiological / neurocognitive approach to personality, then the overlap between temperament, personality and personality disorders becomes more evident. Furthermore, given the mounting evidence that ADHD can persist from childhood into adulthood, it also follows that there should be more focus on the relationship between personality and ADHD [35]. Some authors [36] maintain that is important to describe ADHD in adulthood in terms of general personality structures as it could contribute to a better conceptualization of the disorder. Furthermore, there are suggestions that there is evidence that indicates that developmental factors may contribute to ADHD in ways that are separate from the associated behaviour problems. One could go further by saying that it is important to describe personality disorders (from a neurobiological perspective) in adults with ADHD, as this could aid in describing a possible shared aetiology. In fact one could go as far as to say that incomplete descriptions of Personality Disorders in ADHD continue to place pressure on the validity of the diagnosis in adulthood [2]. Although there have been a number of studies that have focused on the relationship between ADHD and personality, some authors [35] maintain that these studies have focussed on only a narrow range of personality constructs. Table 2 provides a summary of personality constructs that have been investigated in relation to ADHD, as well as how these characteristics may feature in personality disorders.

\begin{tabular}{lll}
\hline Construct & $\begin{array}{l}\text { Characteristic of } \\
\text { ADHD }\end{array}$ & $\begin{array}{l}\text { Characteristic of Cluster B Personality } \\
\text { Disorder }\end{array}$ \\
\hline Sensation Seeking / External stimulation seeking & {$[38,39]$} & Antisocial [49] \\
\hline Behavioural disinhibition / Impulsivity & {$[40,41]$} & $\begin{array}{l}\text { Antisocial and Borderline [45] } \\
\text { Borderline [46, 48, 51] }\end{array}$ \\
\hline Self-regulation & {$[40]$} & Borderline, Antisocial and Histrionic [50] \\
\hline Externalizing problem behaviours & & Axis Il disorders [52] \\
\hline Emotional lability & {$[42]$} & Antisocial [50] \\
\hline Low reward dependence & {$[41]$} & Borderline [44] \\
\hline Uncooperativeness & {$[43]$} & Antisocial and Borderline [45] \\
\hline
\end{tabular}

Table 2. Summary of personality constructs identified in ADHD and possible links with Cluster B disorders

There has traditionally been a great but, arguably unwarranted [43], emphasis on the prevalence of Cluster B personality disorder in adults with ADHD. This study, in effect wants to investigate whether there is some shared neurodevelopmental process in both of these sets of disorders. The argument is based on the following postulates:

- ADHD is a neurodevelopmental disorder and is the result of either maturational lag or maturational deviation 
- In some cases ADHD does not continue beyond adolescence (which is in line with the maturational lag hypothesis), however

- ADHD may continue into adulthood, which cannot be explained fully by the maturational lag hypothesis.

- The is a reportedly high prevalence of personality disorders in adults with ADHD

- There is evidence of both maturational lag and deviation processes in personality disorders.

If these postulates are correct, the question that arises is whether these two disorders could be the result of the same neurodevelopmental process. Most, if not all, of the characteristics mentioned in Table 2 have an underlying neuropsychological or neurobiological correlate. These neurobiological correlates may be the result of either a maturational lag or maturational deviance process, depending on which personality disorder one focuses on. One way of distinguishing between these two hypotheses, would be to consider the course and prognosis of the different personality disorders. Regarding the Cluster B personality disorders, two interesting pictures evolve when reviewing course and prognosis, and these may, arguably be classified as maturational lag or maturational deviation.

\subsection{Maturational lag}

The roots of the development of Antisocial Personality Disorder can be traced to early adolescence (i.e. Conduct Disorder) which then follows an unremitting course, with a variable outcome. There is some evidence that suggests that the symptoms decrease with age [53]. The fact that the symptoms may decrease with age, is somewhat suggestive of a delayed maturation process [54]. A further indication of a maturational lag is the fact that there is excessive theta wave activity, while awake, which is akin to what is evident in younger children [54]. One explanation for this could be the temporal discounting paradigm which quantifies the ability to favour larger, delayed rewards over smaller, more immediate rewards. Temporal discounting matures with age, along with increased impulse control and self-regulation. This maturation seems to be associated with changes in activation of the ventromedial prefrontal cortex, anterior cingulate cortex, ventral striatum, insula, inferior temporal gyrus and posterior parietal cortex [55].

Although it is reported that adults with a histrionic personality disorder display less symptoms as they age [53], it is uncertain whether this is truly due symptoms diminishing due to maturation, or whether this is merely due to a decline in energy levels due to aging.

\subsection{Maturational deviation}

In the case of both borderline and narcissistic personality disorders, the disorders are stable over time showing neither intensifying or decline in symptoms [53]. Unlike antisocial personality disorder, the DSM does not make provision for early identification of these disorders; however, some research does provide some evidence for the early identification of specifically borderline personality disorder [56]. Although there is some evidence of epileptiform activity in borderline personality disorder [57], the prevalence is not high enough to 
substantiate that this disorder is due to abnormal brainwave activity. Abnormal brainwave activity is only one of the many possible neurobiological factors in this disorder and other factors such as neurotransmitter systems, the endogenous opioid system [58] and various sub-cortical areas have been included as possible contributing causes to this disorder. Despite numerous studies thyat have been done, the neurobiology of borderline personality disorder still remains largely unclear [58]. If there is evidence of neurobiological processes, and that symptoms do not appear to improve over time, one could deduce that these (narcissistic and borderline) are due to maturational deviation, rather than maturational lag.

\subsubsection{Method}

This study formed part of a much larger project, and this study itself was larger than what is reported here. The research question for this study is focused exclusively on maturational delay versus maturational deviation. Due to the fact that the existing literature seems to focus mainly on Cluster B personality disorders, and that EEG studies in relation to the research question focus mainly on resting state EEG recordings, this study does the same. Therefore, although there is more information available than reported here, it will be limited to what is pertinent to the research question only.

\subsubsection{Participants}

In order to address the research goals the study utilised purposive sampling methods to identify the ADHD sample. All participants had to be older than 18 years of age and as far as the other including characteristics are concerned, the researchers had to utilise their judgement to identify and select individuals from a target population that qualify for participation in the study, based on the sample characteristics [59]. During the initial phases of the sampling procedure the researchers verbally marketed the research undertaking to professional practitioners (mostly psychiatrists and psychologists). Furthermore participants who were selected on the basis of purposive sampling also nominated acquaintances whom they believed may qualify for participation in the research. In the initial phase the target population was broadly defined by observed ADHD type behaviours that may be explained by the syndrome and may be potentially differentially diagnosed from other clinical conditions.

Participants who were subject to the exclusion criteria were not included in the study. The list of exclusion criteria are informed by similar EEG studies [18, 60-62] which included:

- Psychoactive medication, with the exception of methylphenidate (ADHD related medication), in which case participants were asked to refrain from taking the medication for a minimum of 24 hours prior to the assessment.

- History of a neurological disorder, head injury or CNS infection.

- History of substance use disorder in the previous two months.

- Evidence of another Axis I or Axis II disorder.

- Current diagnosis of hypothyriodism. 
All participants were subject to the clinical interview, and screened for a 'best estimate' diagnosis for ADHD by means of the ASRS-v.I.I. and also with the MCMI-III [63] for differential diagnosis of other clinical syndromes. The nature of these assessment tools and rationale for their use are discussed below. The recruitment of participants resulted in a group of 51 adults with ADHD and a group of 43 adults with no clear indications of a clinical disorder.

For the EEG study an initial 15 potential ADHD research participants were identified from the bigger pool, however, on further investigation 3 participants were excluded from further analysis on the basis that they met the criteria for another clinical condition. Subsequently 12 participants met the operational criteria to constitute the ADHD EEG study population. These participants were first subject to the EEG assessment before the age- and gender- matched nonADHD sample was identified. The reason for this was to ensure that no further participants needed to be excluded and that the non-ADHD sample could be matched on the characteristics of the final ADHD sample. Two individuals were further excluded from the study population on the basis that the one participant experienced excessive drowsiness and another participant presented with significant muscle movement that may confound the obtained results. Subsequently, 10 participants were included in the research sample for the ADHD group. This sample met the necessary operational criteria for the inclusion in the study and produced an EEG reading that is acceptable according to the quality standards. The mean sample age for the ADHD group was 34.4 years. The female to male ratio was 3:1.

Following the identification of the research sample for the experimental group the study set out to identify an age- and gender- matched healthy non-ADHD group. Matched sampling for this group took place by purposively selecting participants from the initial pool of potential participants. The sampling of this group was matched exactly to gender and approximately within a four year range of the target age criterion. Subsequently the non-ADHD research sample that was identified exhibited a mean sample age of 33.6 years with a similar female to male ratio as the experimental group.

\subsubsection{Measurement instruments}

One of the main challenges in this study was to accurately identify adults with a diagnosis of ADHD. Due to the fact that ADHD, specifically in adulthood, is not a widely accepted diagnosis, or in other cases an over diagnosed disorder, one cannot rely only on formal diagnoses made by Mental Health Professionals. Added to this is the problem of a high rate of self-diagnosis of this disorder amongst adults [64], which brings into question relying only on self-report questionnaires to identify possible participants. For this reason, over and above the MCMI-III, a semi-structured interview and a self-report questionnaire were also included.

Semi-Structured Clinical Interview. The interview was conducted by any one of the trained clinical psychologists that formed part of the research team. The purpose of the interview was to ensure that participants met the sampling characteristics mentioned above and to make certain that none of the exclusion criteria were present in the respective population. The interview also obtained information regarding the biographical information of participants. Furthermore it served as a quick screening conformational tool by exploring the presence or absence of the criteria for ADHD in adulthood as proposed by a number of authors [65, 66]. 
Adult ADHD Self-Report Scale (ASRS). The ASRS is not a diagnostic tool but is used as a screening device to screen for signs and symptoms of adult ADHD. The Adult ADHD SelfReport Scale (ASRS) is a self-report 18 question questionnaire which screens adults for ADHD [67]. The ASRS is based on the criteria listed in the DSM IV, on ADHD [68]. Half of the questions focus on inattention and half of the questions focus on hyperactivity [69]. It is a paper pencil questionnaire which is self-scored and only takes 5 minutes to complete [67]. It has a five point Likert scale, where the testee ticks one of five responses, never, rarely, sometimes, often and very often [67]. The ASRS has demonstrated good reliability and validity in clinical and community samples [68]. The ASRS also has high-quality predictive power with values between 57 and 93\%, showing that it can predict ADHD[70]. The ASRS proves good internal consistency with values between 0.75 and 0.89 [69]. Concordance was calculated by looking at the symptom responses of the ASRS and comparing the responses to clinical ratings, of which Cohen's $\mathrm{k}$ was used to assess this concordance [67]. The concordance however varied with a range of.16 to.81, which could be the result of error of measurement or the experience of the clinicians [67]. The total classification accuracy rated at $96 \%$, however, the ASRS showed moderate levels of concurrent validity and sensitivity but high levels of specificity [69].

Millon Clinical Multi-axial Inventory-III. This test is primarily a self-report questionnaire that assesses a wide range of information about an adult's personality and emotional adjustment [71]. Furthermore this instrument was designed as a diagnostic tool that yields information about personality disorders as well as clinical syndromes [72]. The test consists of 175 questions that are forced-choice, true-false items [73]. The MCMI III has 28 sub-scales, of which are categorized into five different categories [71], i.e. Modifying Indices, Clinical Personality Patterns, Severe Personality Pathology, Clinical Syndromes, and Severe Syndromes. For the purposes of this study base rate scores below 75 were considered to be indications of no clinical significance, $75-84$ as indicative of the presence of a personality trait, and 85 and higher as persistent personality traits [73].

The results for the internal consistency was :66 for the compulsive scales and 0.90 for major depression, and the Cronbach alpha's for the remaining 26 scales exceeded.80, showing strong internal consistency [73]. Test-retest reliability scores indicated the lowest score of.82 for debasement and the highest was.96 for somatoform, of which the median test-retest coefficient was.91, which shows stability of the instrument over time [71].

Construct and concurrent validity is tested by looking at how well the instrument performs in different populations and how much value it has in the real world [73]. The manner in which this is achieved was by comparing the MCMI to accepted standards achieved by other tests, comparing the scales on the MCMI to other scales on different tests [73]. It was identified that there is a high correlation between the scales of the MCMI-III and seven different tests, namely the symptom checklist-90, the Beck Depression Inventory, the State-Trait Anxiety Inventory, the General Behaviour Inventory, the Minnesota Multiphasic Personality Inventory (MMPI), the Michigan Alcoholism Screening Test and the MCMI-II [71]. The correlations on most of the scales where good, with some having negative scores, but these items were not related to the specific scales on the MCMI-III. Further evidence to assess how well the MCMI-III scales meas- 
ure what they say they measure is by calculating the positive predictive power, which was remarkable showing a range of.30 to.80 [71]. The MCMI-III has proven construct validity and diagnostic validity, by comparing test items with other tests and by comparing clinical judgement with the results indicated from the scales on the MCMI-III [73].

Biopac MP Systems Hardware. The research question is concerned with the nature of the intracranial electrical currents of adults with ADHD symptomatology. Therefore EEG recording is appropriate for this study in that it records the electrical activity of cortical nerve cells in the brain [74]. It is noteworthy to mention that cortical activity is presented in waveforms and is measured in terms of amplitude and frequency [75]. Amplitude is expressed in microvolts $(\mu \mathrm{V})$, EEG power is defined by the square of amplitude $\left(\mu \mathrm{V}^{2}\right)$ and frequency is defined as the number of oscillations, or cycles, within a given time frame, or epoch, and is measured in hertz $(\mathrm{Hz})[76]$.

This study employed the Biopac MP Systems Hardware [77] for the assessment of cortical activity. The system is considered to be commercial EEG equipment utilised in the data acquisition and analysis for life science research. The recording technique utilised by this system is an ethically approved, non-invasive, safe and painless procedure [78]. In order to ensure the quality of research, the EEG methods employed in this study are informed by various other EEG studies that employed quantitative EEG techniques [75] as well as standardised guidelines for the technologic recording and quantitative analysis of EEG activity in the research context [79].

A final matter to consider in this section is the reliability and validity of EEG recordings. Various researchers report that EEG recordings are reliable, in that the intra-individual stability of EEG is stable over time (over a period of 10 to 90 days) [80,81]. The validity of EEG research depends on the concepts of sensitivity and specificity [76]. In ADHD research, sensitivity refers to the percentage of ADHD individuals who present with an abnormal EEG while specificity reveals the percentage of non-ADHD subjects who indicate a normal EEG [76]. In a literature review of several studies, it was concluded that EEG methods in ADHD research typically demonstrate good sensitivity (90\% to $97 \%$ ) and sound specificity (84\%-94\%)[76].

\subsubsection{Procedure}

All potential participants were required to complete the ASRS and MCMI for screening purposes. Based on the scores on these instruments they were allocated to different groups, or where they did not meet the criteria for any of the groups, were excluded from further studies. As explained previously, the sample for the EEG study was drawn from this pool. Potential participants were approached to participate in the EEG study.

Upon arrival to the research laboratory participants were requested to sit in the allocated chair. The researcher and EEG equipment was situated outside of the participants direct line of sight. Participants were then oriented to the Biopac MP Systems Hardware equipment, and was further provided with an opportunity to ask questions. The researcher enquired about whether participants adhered to the instruction to refrain from the aforementioned substances 24 hours before the assessment. Participants were informed that during the data 
acquisition phase they will engaged in a three minute eyes-closed task. Participants were also instructed to remain as physically still as possible in order to limit muscle contamination throughout the entire assessment, and were requested to avoid speaking during the assessment as a further attempt to avoid contamination of results.

In the data acquisition phase subjects were fitted with an electrocap in accordance with the 10-20 International system of electrode placement. In order to tap the fronto-parietal attention network, electrodes were grouped into three areas: frontal (F3 and F4), frontal midline (Fz) and parietal (P3 and P4) sites (see Figure 1.). EEG signal for all subjects was recorded under an eyes-closed condition. Eye movements were monitored by electrodes placed on the outer canthus of each eye for horizontal movements and by electrodes above the eye for vertical movements. EEG signal was recorded using AcqKnowledge software and BIOPAC MP Systems hardware. Impedance was kept below $5 \mathrm{Kohm}(\mathrm{k} \Omega)$ and a sampling rate of $200 \mathrm{~Hz}$ was applied. Continuous EEG data was reviewed off-line. Segments containing head and eye movement as well as muscle artefact were removed from further analysis. Subsequently, six two second epochs were extracted for the eyes-closed condition and for each of the cortical sites investigated and for the four frequency bands: delta $(1-4 \mathrm{~Hz})$; theta $(4-8 \mathrm{~Hz})$; alpha $(8-13 \mathrm{~Hz})$; and Beta $(13-20 \mathrm{~Hz})$. EEG data was Fast Fourier transformed (FFT) (Hanning window) and subsequently log transformed (In).

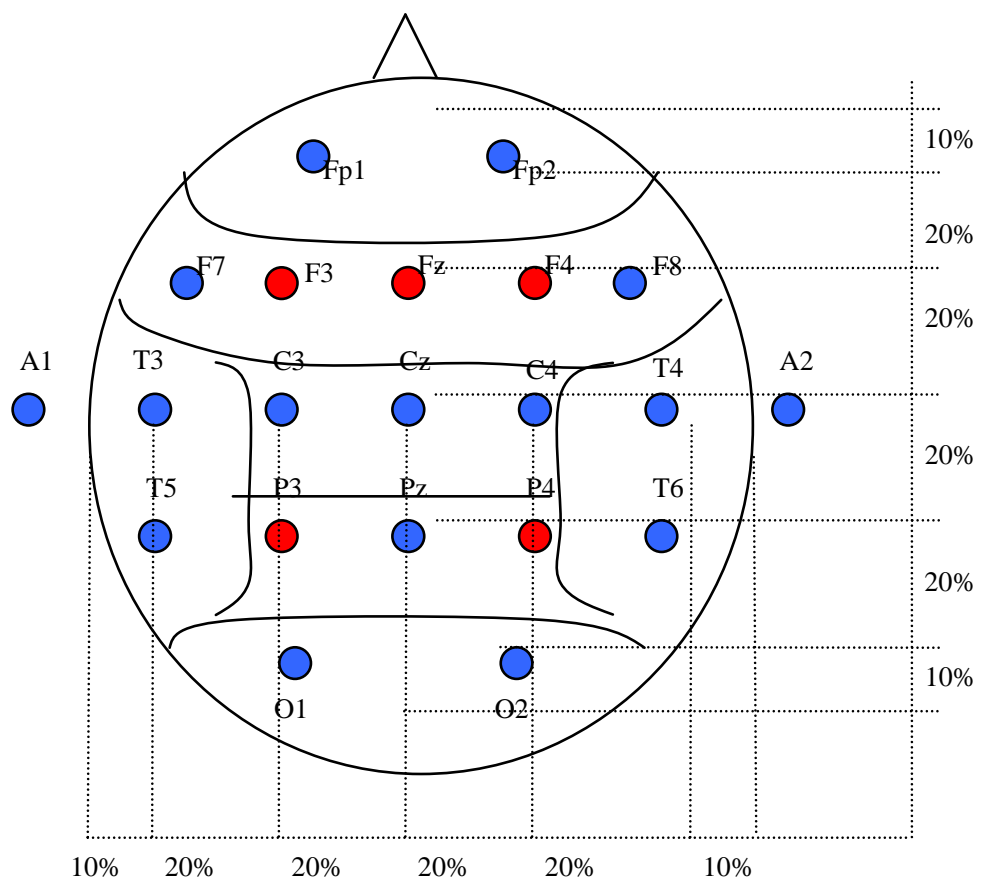

Figure 1. International 10-20 System of Electrode Placement (Adapted from [75]) 


\subsubsection{Results}

\subsubsection{Personality disorder}

In order to gain a meaningful picture of Personality Disorders in ADHD, and therefore a better picture of maturational lag versus maturational deviation, the data gained from the MCMI-III was used in different ways. Firstly the average base rate scores (interval scale) were compared between the groups, thereafter the scores were categorised into 3 categories (Ordinal scale), i.e. $<75,75-84$ and $85>$, where after the groups were compared, and lastly, based on the categorisation of the data, number of personality disorders per individual, per group are reported.

\begin{tabular}{llllll}
\hline & & Histrionic & Narcissistic & Antisocial & Borderline \\
\hline ADHD $(n=51)$ & Mean & 50.6 & 58.5 & 61.4 & 55.4 \\
\hline Std. Dev & 23.6 & 21.7 & 14.3 & 21.7 \\
\hline Min & 0 & 15 & 35 & 0.0 \\
\hline Max & 95 & 110 & 90 & 92.0 \\
\hline Mean & 60.1 & 55.9 & 43.6 & 38.4 \\
\hline & Std. Dev & 23.3 & 20.8 & 19.1 & 22.4 \\
\hline & Min & 4 & 15 & 82 & 0.0 \\
\hline
\end{tabular}

Table 3. Descriptive statistics for the 4 groups for the interpersonal sub-scales

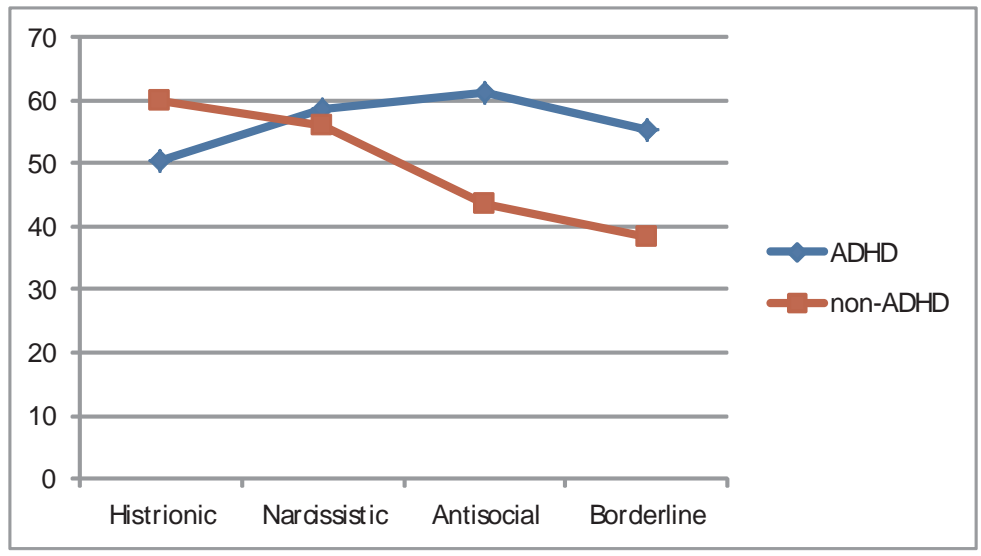

Figure 2. Mean scores of the 4 Cluster B Personality Scales for the 2 groups 
In terms of the average base rate scores, Table 3 and Figure 2 reflected that the two groups were more or less equal in terms of Narcissism and that the non-ADHD group had a higher average score on the Histrionic, but significantly lower scores on both the Anti-Social and Borderline scales (See Tables 3 and 4). Of particular importance is that none of the average scores were higher than 75 , indicating that neither of the two groups displayed typical persistent personality traits.

\begin{tabular}{lllll}
\hline & Histrionic & Narcissistic & Antisocial & Borderline \\
\hline Mann-Whitney U & 861.0 & 980.5 & 502.5 & 612.5 \\
\hline Wilcoxon W & 2187.0 & 1926.5 & 1448.5 & 1558.5 \\
\hline Z & -1.791 & -.882 & -4.521 & -3.678 \\
\hline$p$ & 0.07 & 0.38 & $\mathbf{0 . 0 0 0}^{* * *}$ & $\mathbf{. 0 0 0}^{* * *}$ \\
\hline
\end{tabular}

Where: ${ }^{* * *}: p<0.001$

Table 4. Differences between ADHD and Normal groups for the interpersonal sub-scales

Interpreting only the differences in base rate scores of the MCMI can be misleading, therefore the scores of individuals for each of the scales was categorised into one of three categories, i.e. Low ( $<75)$, High (75-84) or Significant $(84>)$ (See Table 5).

\begin{tabular}{|c|c|c|c|c|c|}
\hline & & Low score & High score & Sign & \\
\hline & & $<75$ & $75-84$ & $85>$ & Total \\
\hline & & $\mathrm{N}$ & $\mathrm{N}$ & $\mathrm{N}$ & $\mathrm{N}$ \\
\hline & $A D H D$ & 42 & 5 & 4 & 51 \\
\hline \multirow[t]{3}{*}{ Histrionic } & nADHD & 30 & 4 & 9 & 43 \\
\hline & Total & 72 & 9 & 13 & \\
\hline & ADHD & 41 & 3 & 7 & 51 \\
\hline \multirow[t]{3}{*}{ Narcissistic } & nADHD & 35 & 2 & 6 & 43 \\
\hline & Total & 76 & 5 & 13 & 94 \\
\hline & ADHD & 37 & 12 & 2 & 51 \\
\hline \multirow[t]{3}{*}{ Anti-social } & nADHD & 39 & 4 & 0 & 43 \\
\hline & Total & 76 & 16 & 2 & 94 \\
\hline & ADHD & 40 & 8 & 3 & 51 \\
\hline \multirow[t]{2}{*}{ Borderline } & nADHD & 41 & 1 & 1 & 43 \\
\hline & Total & 81 & 9 & 4 & 94 \\
\hline
\end{tabular}

Table 5. Number of participants per category of Cluster B Personality scores 
When investigating the data in this way, the results indicate that there were significant differences between the 2 groups on all of the subscales (See Table 6).

\begin{tabular}{lllll}
\hline & Histrionic & Narcissistic & Borderline & Anti-social \\
\hline Chi-Square & 79.43 & 96.53 & 118.5 & 98.64 \\
\hline Df & 2 & 2 & 2 & 2 \\
\hline Significance & $.000^{* * *}$ & $.000^{* * *}$ & $.000^{* * *}$ & $.000^{* * *}$ \\
\hline
\end{tabular}

Where: ${ }^{* * *}: p<0.0001$

Table 6. Chi Square for differences between the 2 groups

Given these results, a frequency analysis was done to determine how many elevated scores (85>) an individual participant had (See Table 7).

\begin{tabular}{ccc}
\hline Number of Personality Disorders & ADHD & nADHD \\
\hline 0 & $39(76.5 \%)$ & $39(90.7 \%)$ \\
\hline 1 & $9(17.6 \%)$ & $4(9.3 \%)$ \\
\hline 2 & $2(3.9 \%)$ & $0(0.0 \%)$ \\
\hline 3 & $1(2 \%)$ & $0(0.0 \%)$ \\
\hline Total & 51 & 43 \\
\hline
\end{tabular}

Table 7. Number of Personality Disorders per group

These results, from a maturational deviation perspective are meaningful in that the majority of the ADHD participants (76\%) did not show any evidence of a Cluster B Personality Disorder. If one assumes that ADHD is due to maturational lag, and that Cluster B Personality Disorders are also due to maturational lag, then these results seriously challenge this assumption. Given the fact that a higher percentage of ADHD (27.5\%) showed indications of one or more Cluster B Personality Disorders than the non-ADHD group (9.3\%), there seems to be evidence of a possible maturational deviation process.

\subsubsection{EEG results}

This part of the study focussed the brain's intracranial electrical currents and potentials, in other words cortical activity, of adults with ADHD, and those with no ADHD symptomatology. The patterns that are of particular concern are the activity (elevation or suppression) of the four frequency bands (delta, theta, alpha and beta). 
The study focused on two domains of investigation: power spectral and ratio coefficients. Power spectral studies concerns the calculation of absolute and relative power estimates [20].

- Power spectral density or the power spectrum “... reflects the 'frequency content' of the signal or the distribution of signal power over frequency" [82, p. 806]. For the power spectral domain the analysis was concerned with two spectral parameters, i.e.:

- Relative power is determined by the amount of EEG activity in a frequency band divided by the sum of the other bands [75].

- Absolute power is the amount for one specific frequency band without its relationship to the other bands [79].

- Ratio coefficients refers to the ratio between power in different frequency bands [20].

These two domains of investigation were selected on the basis that they are the most common and often preferred means of investigation for ADHD studies [20]. The mean values obtained for the ADHD and non-ADHD group, per area of the brain investigated and per frequency cluster were employed in obtaining the values for the domains of investigation. The abovementioned equations were applied and subsequently, the absolute, relative and power ratios were determined. Note that for this study frequency parameters are set as follows: delta (1-4Hz); theta (4-8Hz); alpha (8-13Hz); and Beta (13-20Hz). The Greek symbols employed to denote the different waves include: delta as $\delta$; theta as $\theta$; alpha as $\alpha$; and finally beta as $\beta$. As far as the experimental condition is concerned, the abbreviation of EC is employed.

In order to address the research question a between-subjects analysis of diagnostic group differences was applied. Seeing that the small sample size was not representative of the greater population, nonparametric statistical procedures were employed [85]. Subsequently the Mann-Whitney U-test was applied with the use of SPSS software. The Mann-Whitney U test is the nonparametric alternative to an independent $\mathrm{t}$-test. The Mann-Whitney U test is appropriate for the between-subjects analysis because it compares differences between two independent groups, in this case ADHD with non-ADHD [85].

In Table 8 the absolute mean power $\left(\mu \mathrm{V}^{2}\right)$ and Table 9 the relative mean power for the different frequency bands for the different cortical areas across the different conditions are reported. The table is formatted in this way as to compare the ADHD sample with the non-ADHD sample according to the four frequency clusters and according to the area of the brain investigated.

The results of the resting EEG reveal elevated ADHD relative theta activity at frontal midline sites. This finding is consistent with childhood and adolescent research that is suggestive of a maturational lag and developmental deviation profile. Increased relative theta activity is also indicated in the ADHD studies of $[18,19]$ as well as Clarke et al. (2008b) at frontal midline sites. Although it was also expected that theta activity would be elevated in frontal sites, this was not confirmed in the present study. Moreover, the elevation or decrease of theta activity is not documented widely for parietal sites in ADHD literature. However, an interesting observation that was not indicated for the initial expectations for the current study is the presence of decreased absolute theta for the ADHD sample at parietal 
sites. The reduction of absolute theta at parietal sites is also not supported in the other six ADHD studies mentioned [10, 18, 19, 61,31,33].

The results of the resting EEG further reveal elevated theta/beta and theta/alpha ratios at frontal midline sites. These results are consistent with child and adolescent research that are suggestive of a developmental deviation profile. These results are also indicated in the ADHD studies of $[18,19,33]$.

The resting EEG of the current study also indicates decreased relative beta power for the ADHD sample in the frontal midline area. These results are in line with child and adolescent research that are suggestive of a developmental deviation profile. Of the six ADHD studies $[10,18,19,31,33,61]$ identified in the current author's literature search, none of the authors confirm such results. Also, although decreased beta power was expected for frontal and frontal midline sites, the finding was only apparent for the frontal midline area.

\begin{tabular}{|c|c|c|c|c|c|c|}
\hline & ADHD & non-ADHD & Mann-Whitney U & Wilcoxon W & $\mathbf{Z}$ & Between group differences \\
\hline & & & & & & $\mathrm{p}$ \\
\hline \multicolumn{7}{|c|}{ Frontal } \\
\hline$\delta$ & 0.0191 & 0.0210 & 35.5 & 90.5 & -0.78 & 0.44 \\
\hline$\theta$ & 0.0549 & 0.0588 & 38.0 & 93.0 & -0.57 & 0.60 \\
\hline a & 0.0444 & 0.0476 & 34.5 & 89.5 & -0.86 & 0.40 \\
\hline$\beta$ & 0.0171 & 0.0178 & 38.5 & 93.5 & -0.54 & 0.59 \\
\hline \multicolumn{7}{|c|}{ Midline } \\
\hline$\delta$ & 0.0106 & 0.0070 & 34.0 & 79.0 & -0.91 & 0.40 \\
\hline$\theta$ & 0.0304 & 0.0241 & 35.0 & 80.0 & -0.82 & 0.45 \\
\hline$a$ & 0.0234 & 0.0206 & 38.5 & 83.5 & -0.53 & 0.60 \\
\hline$\beta$ & 0.0082 & 0.0074 & 39.5 & 84.5 & -0.454 & 0.66 \\
\hline \multicolumn{7}{|c|}{ Parietal } \\
\hline$\delta$ & 0.0171 & 0.0317 & 20.5 & 75.5 & -2.01 & $0.04 *$ \\
\hline$\theta$ & 0.0459 & 0.0696 & 20.5 & 75.0 & -2.05 & $0.04 *$ \\
\hline$a$ & 0.0358 & 0.0513 & 21.0 & 76.0 & -1.96 & 0.05 \\
\hline$\beta$ & 0.0129 & 0.0211 & 19.5 & 74.5 & -2.09 & $0.04 *$ \\
\hline
\end{tabular}

Table 8. Absolute Mean Power $\left(\mu V^{2}\right)$ for the ADHD $(n=10)$ and the non-ADHD $(n=9)$ Groups 


\begin{tabular}{|c|c|c|c|c|c|c|}
\hline & ADHD & non-ADHD & Mann-Whitney U & Wilcoxon W & $\mathbf{Z}$ & Between group differences \\
\hline & & & & & & $\mathrm{p}$ \\
\hline \multicolumn{7}{|c|}{ Frontal } \\
\hline$\delta$ & 13.0985 & 13.5419 & 39.5 & 84.5 & -0.45 & 0.50 \\
\hline$\theta$ & 40.7944 & 40.6344 & 39.0 & 84.0 & -0.49 & 0.66 \\
\hline$a$ & 33.4839 & 33.4904 & 40.0 & 85.0 & -0.41 & 0.72 \\
\hline$\beta$ & 12.6232 & 12.3331 & 42.0 & 87.0 & -0.25 & 0.80 \\
\hline \multicolumn{7}{|c|}{ Midline } \\
\hline$\delta$ & 12.6778 & 11.7963 & 34.0 & 79.0 & -0.91 & 0.40 \\
\hline$\theta$ & 41.9948 & 40.9362 & 0.00 & 45.0 & -3.68 & $0.000^{* * *}$ \\
\hline$a$ & 33.6352 & 35.0017 & 11.0 & 64.0 & -2.94 & $0.004^{* *}$ \\
\hline$\beta$ & 11.6922 & 12.2656 & 15.0 & 70.0 & -2.45 & $0.01^{* *}$ \\
\hline \multicolumn{7}{|c|}{ Parietal } \\
\hline$\delta$ & 14.0345 & 16.4011 & 20.5 & 75.5 & -2.01 & $0.04^{*}$ \\
\hline$\theta$ & 40.8777 & 40.1942 & 30.0 & 75.0 & -1.23 & 0.24 \\
\hline$a$ & 33.1763 & 31.1389 & 29.0 & 74.0 & -1.31 & 0.21 \\
\hline$\beta$ & 11.9112 & 12.2660 & 26.0 & 81.0 & -1.55 & 0.13 \\
\hline
\end{tabular}

Table 9. Relative Mean Power $\left(\mu V^{2}\right)$ for the ADHD $(n=10)$ and the non-ADHD $(n=9)$ Groups

The results of the resting EEG further reveal decreased absolute alpha and beta activity for the ADHD sample at parietal sites. These findings are observed in child and adolescent research that are consistent with the maturational lag and developmental deviation profile. The results however have not been indicated in the six ADHD studies identified in the literature search.

\begin{tabular}{|c|c|c|c|c|c|c|}
\hline & ADHD & non-ADHD & $\begin{array}{l}\text { Mann-Whitney } \\
\text { U }\end{array}$ & Wilcoxon W & $\mathbf{Z}$ & $\begin{array}{l}\text { Between group } \\
\text { differences (p) }\end{array}$ \\
\hline \multicolumn{7}{|c|}{ Frontal } \\
\hline$\theta: \beta$ & 3.28 & 3.30 & 42.0 & 97.0 & -0.25 & 0.84 \\
\hline$\theta: a$ & 1.23 & 1.23 & 39.5 & 94.5 & -0.45 & 0.66 \\
\hline \multicolumn{7}{|c|}{ Midline } \\
\hline$\theta: \beta$ & 3.69 & 3.33 & 6.0 & 51.0 & -3.19 & $0.001^{* *}$ \\
\hline$\theta: a$ & 1.28 & 1.17 & 2.0 & 47.0 & -3.52 & $0.000^{* \star *}$ \\
\hline \multicolumn{7}{|c|}{ Parietal } \\
\hline$\theta: \beta$ & 3.63 & 3.98 & 21.0 & 66.0 & -1.96 & 0.05 \\
\hline$\theta: a$ & 1.27 & 1.34 & 43.0 & 98.0 & -0.16 & 0.91 \\
\hline
\end{tabular}

Table 10. Mean Power Ratio Values for the ADHD $(n=10)$ and the $n \operatorname{ADHD}(n=9)$ groups 


\subsubsection{Conclusion}

The current study's results contribute to the neurobiological and pathophysiological information of ADHD and are important for the advancement of aetiological theorising in the field. Of particular relevance is the interpretation of data in accordance to the maturational lag and developmental deviation model. The abovementioned results are consistent with child and adolescent research that support both models. Hence this brings forth the question of which model more adequately describes the aetiological bases that may be related to the phenomenon of ADHD.

Given the overlap between the neurocognitive symptoms between ADHD and Personality Disorders (specifically Cluster B), the first part of the study investigated the prevalence of Personality Disorders in ADHD. The rationale for this was twofold, i.e. there is evidence to suggest that Cluster B disorders may be the result, as is the case with ADHD, of maturational lag, therefore, if this is true, all adults with ADHD should show signs of at least one Cluster B personality disorder. The results of the study indicated that the majority of the adults with ADHD did not show any significant signs of a Cluster B personality disorder. However, there were more ADHD adults showing signs of more than one personality disorder than those adults without ADHD. If one stays with the assumption that there is a neurocognitive component to personality disorders, this may be indicative of maturational deviation.

These findings seem to suggest that (1) ADHD cannot be viewed as a homogeneous disorder with the same underlying neurodevelopmental processes, and (2) childhood ADHD does not necessarily progress into a personality disorder (see Figure 6), therefore there is room for both an Axis I and Axis II diagnosis in adults with ADHD. One of the problems considering ADHD as a homogenous disorder is that it may suggest a single course with a single outcome. Research, however, suggests that there may be multiple outcomes, i.e. remission in adolescence or continuation into adulthood. If there is an assumption of multiple outcomes, it should firstly indicate that this is not a homogenous disorder, and secondly it implies that there are different etiological pathways as well. Before one can draw a final conclusiuon about these statements, it is important to also review the EEG results of the ADHD participants.

In order to further investigate the maturational lag vs. maturational deviation theory of ADHD, an EEG study, was done on a smaller sample. The maturational lag model suggests that ADHD behaviours are a consequence of a neurodevelopmental lag [8]. It further denotes that individuals with ADHD symptoms present with cortical activity patterns that are similar to that witnessed in younger children [8, 20]. Moreover it is accepted that cortical development is expected to 'catch up' and remit in adolescence [6]. The developmental deviation model denote that the cortical activity of individuals with ADHD symptoms are not considered normal at any age and is not likely to mature in a normal fashion [20]. 


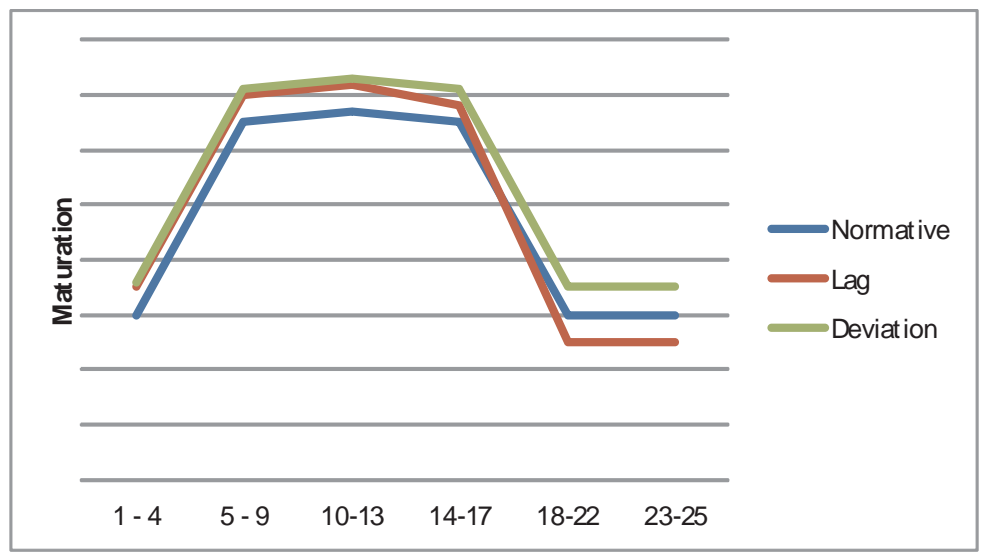

Figure 3. Comparison of normative, maturational lag and maturational deviation models of slow wave activity across developmental stages

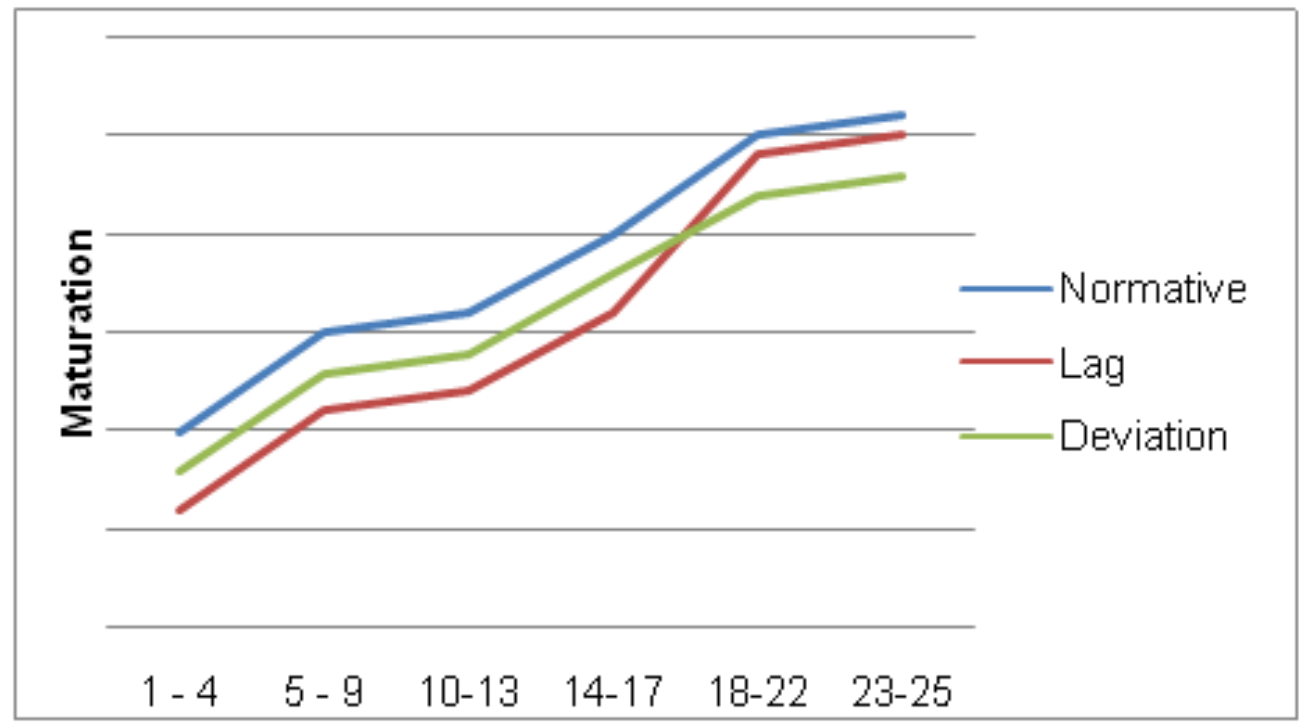

Figure 4. Comparison of normative, maturational lag and maturational deviation models of fast wave activity across developmental stages

As mentioned already, the results of the current study are in line with the ADHD results of $[10,18,19,33]$ who indicate elevated slow wave activity and increased theta/beta and theta/ alpha ratios. Seeing that EEG aberrances are clearly indicated in adult samples, it does not confirm the maturational lag's assumption that cortical maturation will eventually 'catch up' 
$[6,20]$. Instead, the data suggests that ADHD symptoms do persist for some individuals into adulthood. The results further support the developmental deviation, which suggests that ADHD behaviours are related to the disorganisation of wave activity that deviates from normal development $[17,20]$. The deviation is revealed in the results wherein the cortical activity patterns remain aberrant and have not normalised in the ADHD sample. Taken together, the results of the current study confirms [18] notion that since abnormalities of the EEG persists into adulthood for the ADHD sample, the data is indicative of a more persistent developmental deviation for some individuals with the disorder and that not all individuals who present with the disorder will eventually outgrow it.

Up to this point the results of the resting EEG suggests that the data obtained is more suggestive of a developmental deviation than a maturational lag. However, as mentioned already, the results of the current study indicates increased relative theta and consequently elevated theta/ beta and theta/alpha ratios as well as decreased relative beta at frontal midline sites for the ADHD sample in comparison with controls. This profile displays an elevation in slow wave activity and a decrease in fast wave activity. Although this profile is clearly indicated in developmental deviation and maturational lag models, the maturational lag model provides the qualitative and aetiological information that links this profile with ADHD behaviours.

EEG support of the maturational lag model reveals in its findings cortical activity patterns that are similar to that witnessed in younger children [10, 20]. In accordance to Kinsbourne [5], the father of the model's ideas, the cortical activity patterns that limit the performance of younger children are synonymous to that which typically compromises the performance of individuals with ADHD symptomatology [10, 20]. Recent normative databases suggest that absolute and/or relative slow wave activity (delta and theta) is elevated in childhood and is the highest shortly before puberty, where after it declines by $60 \%$ and finally slows down in its decline after the age of 17 [83, 84] (see Figure 3). Following puberty, fast wave activity (alpha and beta) reportedly increases [86]. Finally, between the ages of 25 to 30 years the cortical thickening and thinning (myelination) stabilises and the process of growth spurts and oscillations in terms of cortical activity lessens and normalises [86]. In relation to normative EEG data it is evident that the increase in slow wave activity and decrease in fast wave activity would be more evident in younger children before puberty commences. Hence it appears that the ADHD type behaviours of the current ADHD sample may be aetiologically related to the patterns of cortical activity that typically limit the performance of younger children.

The abovementioned paragraphs elicit information that has implications for the interpretation and advancement of aetiological theorising according to EEG-based models of ADHD. The developmental deviation denotes that the EEG aberrances observed in individuals with ADHD symptoms are not normal in individuals of any age [20]. However, as indicated above, the cortical activity patterns observed in the ADHD sample is synonymous to that which is often observed in younger children. Hence, the data supports the assumption that cortical maturation deviates from normal development and that the deviation is more persistent; however, it does not support the notion that the resting EEG observed is not similar to patterns witnessed at any particular age. Also, the presence of this profile in ADHD EEG research does not automatically serve as evidence of a maturational lag. The reason for this 
is because the observation of EEG activity, that is similar to that witnessed in younger children in one point in time, does not suggest that those patterns will eventually 'catch up'.

A further matter to consider in relation to the resting EEG of the current study is the posterior-anterior time course of cortical development. It is evident that the results of the current study yield EEG aberrances in parietal, frontal and frontal midline sites for the ADHD sample. As discussed previously, the posterior-anterior time course of cortical development suggests that the cortical activity in posterior regions mature more rapidly than frontal regions [87]. When cortical development follows this pathway, delta, theta and alpha develop first from birth in occipital regions and only appear later in parietal and central regions and finally in frontal regions [26].

The results of the current study indicate deviations in the EEG for the ADHD from the control group that are present in early-maturing (parietal area) and later-maturing (frontal and frontal midline area) sites. If maturation were seen to 'catch up' in the ADHD sample, then the greatest between- group differences would only have been indicated at frontal sites [26]. Hence, the data is not suggestive of development that is slow to 'catch up' but again suggests that development in the ADHD sample is indicating a more persistent deviation and disorganisation of wave activity [20,30]. In Figure 5, a summary is provided of evidence for both a maturational lag and deviance model.

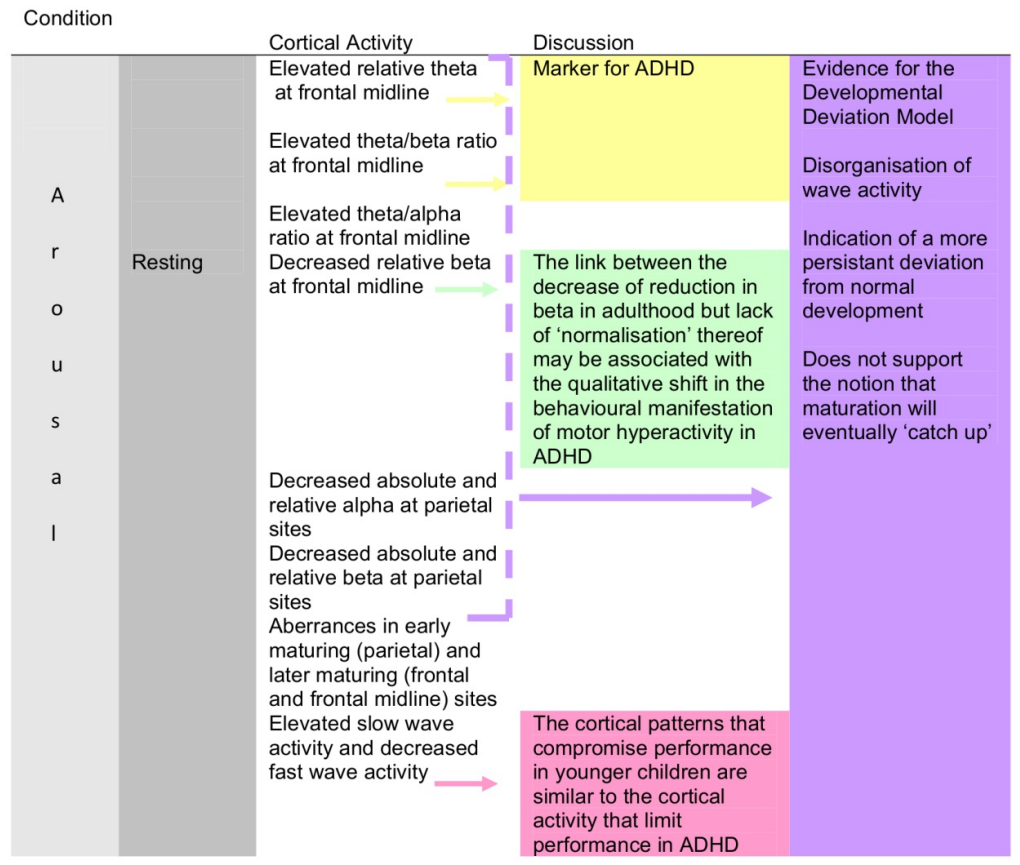

Figure 5. Cortical Activity Patterns of ADHD in Resting Conditions 
It must be emphasised that this study was exploratory in nature, and in many ways it resulted in more questions than answers. What the study did do however, was to highlight some problems in our interpretation of quantitative data. The first of these is the problem of the average. The conclusion drawn from averages does not include a satisfactory explanation for the variance, i.e. in terms of maturational lag, as the findings suggest that there is a distinct possibility that some of these reach cortical maturity at the same rate as non-ADHD children (i.e. those at the higher end of the distribution), and that there are those who may reach this much longer after the 3 year average (i.e. those at the lower end of the distribution). At both ends of the distribution, it opens the possibility for maturational deviance as symptoms are present, but cannot be explained fully by the maturational lag theory (See Figure 6). In line with this above argument, even within studies, not all cortical areas are affected in the same way. This is, in essence, not problematic, however, formulating a general maturational lag model is, as it seems to imply that there is general maturational lag. Furthermore there are studies that report maturational lag, but include discrepant findings in cortical areas which are explained asymmetrical maturation. The question that arises is whether this should then be considered as maturational lag or maturational deviance.

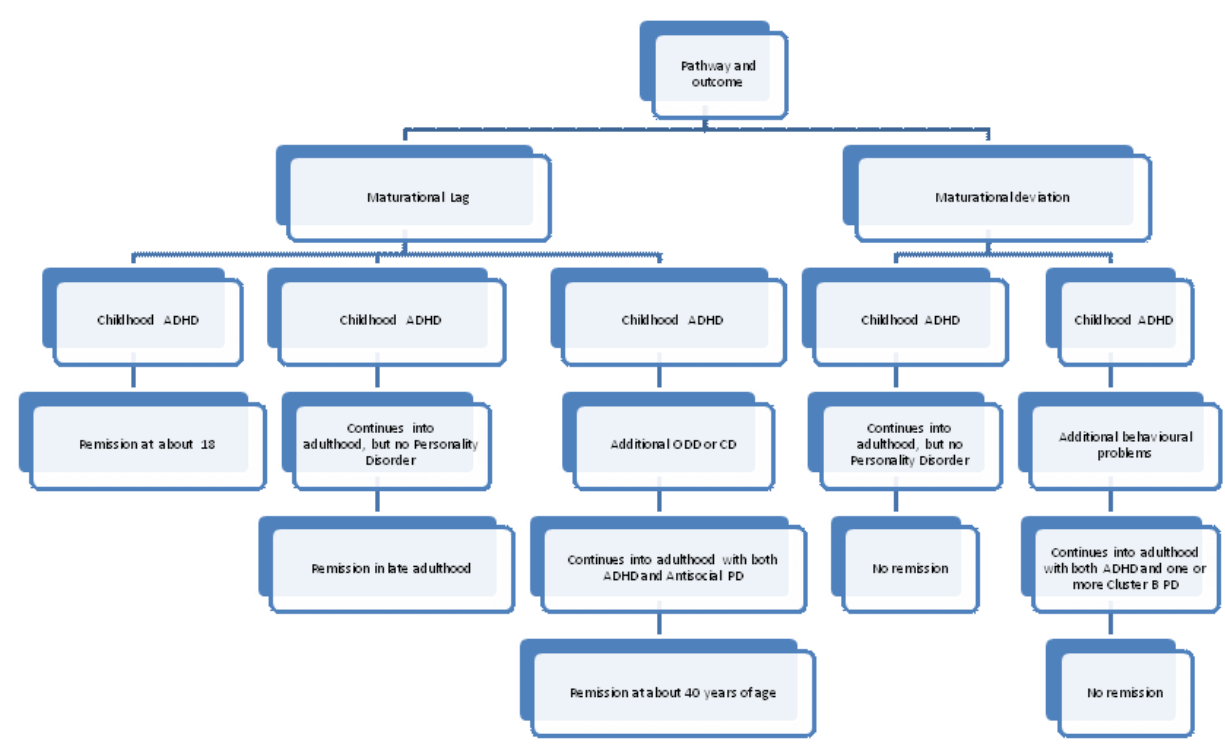

Figure 6. Multiple outcomes of ADHD in adulthood

A common theme which runs through all the studies, and may account for many of the comments above, is that ADHD is often considered to be a homogenous disorder. It is quite possible that maturational lag would best account for a certain sub-group, and deviance for others (See Figure 6). If we are going to gain more insight into the etiology of 
this disorder, we need to review our research methodologies. It is argued that many of the confounding / contradictory results is the way in which studies are conceptualised. In this regard, the sampling of participants needs to be more focused, as current studies seem to include mainly the combined sub-type of ADHD [6].If this were true, it would not be inaccurate to state that very little is known about brain maturation in children with the inattentive subtype. It is therefore imperative that sampling be done much more specifically and that subtypes are compared to each other. Furthermore, one needs to deviate from the common practice to exclude participants with both ADHD and comorbid conditions and rather group these participants together based on disorders that are alike in both symptomotology and theoretical etiology.

\section{Author details}

Alban Burke and Amanda Edge

Department of Psychology, University of Johannesburg, South Africa

\section{References}

[1] www.dsm5.org

[2] Miller TW, Nigg JT, Faraone, SV. Axis I and II comorbidity in adults with ADHD. Journal of Abnormal Psychology 2007; 116(3) 519-528.

[3] Anckarsäter H, Stahlberg O, Larson T, Hakansson C, Jutblad S-B, Niklasson L, Nyden A, Wentz E, Westergren S, Cloninger R, Gillberg C, Rastam M. The Impact of ADHD and Autism Spectrum Disorders on Temperament, Character, and Personality Development. American Journal of Psychiatry 2006; 163 1239-1244.

[4] Nigg JT, Goldsmith HH, Sachek J. Temperament and Attention Deficit Hyperactivity Disorder: The Development of a Multiple Pathway Model. Journal of Clinical Child and Adolescent Psychology 2004; 33(1) 42-53.

[5] Kinsbourne M. Minimal brain dysfunction as a neurodevelopmental lag. Annals of the New York Academy of Sciences 2004; 205 268-273.

[6] Rubia K. Neuro-anatomic evidence for the maturational delay hypothesis of ADHD. Proceedings of the National Academy of Sciences 2007; 104 19663-19664.

[7] Shaw P, Gogtay N, Rapoport J. Childhood psychiatric disorders as anomalies in neurodevelopmental trajectories, Human BrainMapping 2010; 31 917-925.

[8] Clarke, AR, Barry, RJ, Dupuy, FE, McCarthy, R, Selikowitz, M, Heaven, PCL. Childhood EEG as a predictor of adult attention-deficit/hyperactivity disorder. Clinical Neurophysiology 2011, 122 73-80. 
[9] Barry, RJ, Clarke, RA, Johnstone, SJ. A review of electrophysiology in attention-deficit/hyperactivity disorder: I. qualitative and quantitative electroencephalography. Clinical Neurophysiology 2003; 114 171-183.

[10] [10] Clarke AR, Barry RJ, Heaven PCL, McCarthy R, Selikowitz M, Byrne M K. EEG in adults with attention-deficit/hyperactivity disorder. International Journal of Psychophysiology 2008; 70 176-183.

[11] Clarke AR, Barry RJ, McCarthy R, Selikowitz, M. Electroencephalogram differences in two subtypes of attention-deficit/hyperactivity disorder. Psychophysiology 2001; 38 212-221.

[12] Lubar JF, Bianchini K, Calhoun W, Lambert E, Brody, Z, Shabsin H. Spectral analysis of EEG differences between children with and without learning disabilities. Journal of Learning Disabilities 1985; 18 403-408.

[13] Lubar JF. Discourse on the development of EEG diagnostic and biofeedback for attention-deficit/hyperactivity disorders. Biofeedback Self Regulation 1991; 16 201-225.

[14] Mann CA, Lubar, JF, Zimmerman, AW, Miller, Muenchen RA. Quantitative analysis of EEG in boys with attention-deficit-hyperactivity disorder: Controlled study with clinical implications. Pediatric Neurology 1992; 8 30-36.

[15] Matsuura M, Okubo, Y, Toru M, Kojima T, He Y, Hou Y, Shen Y, Lee, CK. A crossnational EEG study of children with emotional and behavioural problems: a WHO collaborative study in the Western Pacific Region. Biological Psychiatry 1993; 34 59-65.

[16] Satterfield JH, Schell AM, Backs RW, Hidaka, KC. A cross-sectional and longitudinal study of age effects of electrophysiological measures in hyperactive and normal children. Biological Psychiatry 1984;19 973-990.

[17] Klinkerfuss GH, Lange PH, Weinberg, WA, O'Leary, JL. Electroencephalographic abnormalities of children with hyperkinetic behavior. Neurology 1965; 15883 - 891.

[18] Bersnahan SM, Anderson, JW, Barry, RJ. Age-related changes in quantitative EEG in attention-deficit/hyperactivity disorder. Society of Biological Psychiatry 1999; 46 1690-1697.

[19] Bersnahan, SM, Barry, RJ. Specificity of quantitative EEG analysis in adults with attention deficit hyperactivity disorder. Psychiatry Research 2002; 112 133-144.

[20] Barry, RJ, Clarke, RA, McCarthy R, Selikowitz M, Rushby JA, Ploskova, E. EEG differences in children as a function of resting-state arousal level. Clinical neurophysiology 2004; 115 402-408.

[21] Chabot RJ, Serfontein G. Quantitative electroencephalographic profiles of children with attention deficit disorder. Biological Psychiatry 1996; 40 951-963. 
[22] Clarke AR, Barry RJ, McCarthy R, Selikowitz M. EEG analysis in attention-deficit/ hyperactivity disorder: a comparative study of two subtypes. Psychiatry Research 1998; 81 19-29.

[23] Clarke AR, Barry, RJ, Bond D, McCarthy R, Selikowitz M. Effects of stimulant medications on the EEG of children with attention-deficit/hyperactivity disorder. Psychopharmacology 2002; 164 277-284.

[24] Defrance JF, Smith S, Schweitzer FC, Ginsberg I, Sands S. Topographical analysis of attention disorders of childhood. International Journal of Neuroscience 1996;87 41-61.

[25] El-Sayed EM, Larsson JO, Persson HE, Rydelilus, P-A. Altered cortical activity in children with attention-deficit/hyperactivity disorder during attentional load task. Journal of American Academy of Child and Adolescent Psychiatry 2002; 41(7) 811-819.

[26] Hobbs MJ, Clarke AR, Barry, RJ, McCarthy, R, Selikowitz, M. EEG abnormalities in adolescent males with AD/HD. Clinical Neurophysiology 2007; 118 363-371.

[27] Schmidt, RG, Tirsch, WS, Reitmeir P. Correlation of developmental neurological findings with spectral analytical EEG evaluations in pre-school age children. Electroencephalography and Clinical Neurophysiology 1997; 103 516-527.

[28] Clarke AR, Barry RJ, McCarthy R, Selikowitz, M. Age and sex effects in the EEG: Differences in two subtypes of attention-deficit/hyperactivity disorder. Clinical Neurophysiology 2001; 112, 815-826.

[29] Hermens DF, Soei EXC, Clarke SD, Kohn, MR, Gordon E, Williams LM. Resting EEG theta activity predicts cognitive performance in attention-deficit hyperactivity disorder. Pediatric Neurology 2005; 32(4) 248-256.

[30] Alexander D M, Hermens DF, Keage, HAD, Clark CR, Williams LM, Kohn, MR, Clarke SD, Lamb C, Gordon E. Event-related wave activity in the EEG provides new marker of ADHD. Clinical Neurophysiology 2008; 119, 163-179.

[31] Loo KS, Sigi Hale T, Macion J, Hanada G, McGough JJ, McCracken JT, Smalley SL. Cortical activity patterns in ADHD during arousal, activation and sustained attention. Neuropsychologia 2009; 47 2114-2119.

[32] Tian L, Jiang T, Liang M, Zang Y, He Y, Sui M, Wang Y. Enhanced resting-state brain activities in ADHD patients: A fMRI study. Brain and Development 2008; 30 342-348.

[33] van Dongen-Boomsma M, Lansbergen M M, Bekker, E M, Kooij J-J S, van der Molen M, Kenemans JL, Buitelaar, J K. Relation between resting EEG to cognitive performance and clinical symptoms in adults with attention-deficit/hyperactivity disorder. Neuroscience Letters 2010; 469 102-106.

[34] Clark L A. Temperament as a Unifying Basis for Personality and Psychopathology. Journal of Abnormal Psychology 2005; 114(4) 505-521. 
[35] Parker JDA, Majeski SA, Collin, VT. ADHD symptoms and personality: relationships with the five-factor model. Personality and Individual Differences 2004; 36 977-987.

[36] Valero S, Ramos-Quiroga A, Gomá-i-Freixanet M, Bosch R, Gomómez-Barros N, Nogueira M, Palomar G, Corrales M, Casas M. Personality profile of adult ADHD: The alternative five factor model. Psychiatry Research 2012; http://dx.doi.org/10.1016/ j.psychres.2011.11.006

[37] Martel M, Nigg JT. Child ADHD and personality / temperament traits of reactive and effortful control, resiliency, and emotionality. Journal of Child Psychology and Psychiatry 2006; 47 (11), 1175-1183.

[38] White JD. Personality, temperament and ADHD: A review of the literature. Personality and Individual differences 1999; 27 589-598.

[39] Shaw GA, Gambria LM. Task unrelated thoughts of college students diagnosed as hyperactive in childhood. Developmental Neuropsychology 1993; 9 17-30.

[40] Barkley RA. Behavioral inhibition, sustained attention, and executive functions: constructing a unifying theory of ADHD. Psychological Bulletin 1997; 121 65-94.

[41] Shea T, Fisher, BE. Self ratings of mood levels and mood variability as predictors of Junior 1-6 impulsivity and ADHD classroom behaviors. Personality and Individual Differences 1996; 20 209-214.

[42] John OP, Caspi A, Robins RW, Moffit TE, Stouthamer-Loeber M. The 'little five": exploring the nomological network of the five-factor model of personality in adolescent boys. Child Development 1994; 65 160-178.

[43] Faraone SV, Kunwar A, Adamson J, Biederman, J. Personality traits among ADHD adults: implications of late-onset and sub-threshold diagnoses. Psychological Medicine 2009; 39(45) 685-693.

[44] Reich DB, Zanarini MC, Fitzmaurice G. Affective lability in bipolar disorder and borderline personality disorder. Comprehensive Psychiatry 2012; 53(4) 230-237.

[45] Beauchaine TP, Klein DN, Crowell SE, Derbridge C, Gatzke-Kopp L. Mutlifinality in the development of personality disorders: A Biology x Sex x Environment interaction model of antisocial and borderline traits. Development and Psychopathology 2009; 21(3) 735-770.

[46] Snyder S, Pitts WM, Pokorny, AD. Affective and behavioural features of DSM-III borderline personality disorder. Are they valid? Psychopathology 1985; 18(1) 3-10.

[47] Blonigen DM, Littlefield AK, Hicks BM, Sher, KJ. Course of Antisocial Behavior during Emerging Adulthood: Developmental Differences in Personality. Journal of Research in Personality 2010; 44(6) 729-733.

[48] Speranza M, Revah-Levy A, Cortese S, Falissard B, Pham-Scottez A, Corcos, M. ADHD in adolescents with borderline personality disorder. BMC Psychiatry 2010; 11 158. 
[49] Ball SA, Carroll KM, Rounsaville BJ. Sensation Seeking, substance abuse, and psychopathology in treatment -seeking and community cocaine abusers. Journal of Consulting and Clinical Psychology 1994; 62(5) 1053-1057.

[50] Sarkar J, Adshead G. Personality disorders as disorganization of attachment and affect regulation. Advances in Psychiatric Treatment 2006; 12 297-305.

[51] Lampe K, Konrad K, Kroener S, Fast K, Kunert HJ, Herpertz SC. Neuropsychological and behavioural disinhibition in adult ADHD compared to borderline personality disorder. Psychological Medicine 2007; 37 1717-1729.

[52] Reimherr FW, Marchant BK, Williams ED, Strong RE, Halls C, Soni P. Personality disorders in ADHD Part 3: Personality disorder, social adjustment, and their relation to dimensions of adult ADHD. Annals of Clinical Psychiatry 2010; 22(2) 103-112.

[53] Sadock BJ, Sadock VA. Kaplan \& Sadock's Synopsis of Psychiatry (9 ${ }^{\text {th }}$ Ed.). Philadelphia: Lippincott: Williams \& Wilkins; 2003.

[54] von Krosigk B. Personality Disorders. In: Burke A. (ed.) Abnormal Psychology: A South African Perspective ( $2^{\text {nd }}$ Ed.). Cape Town: Oxford University Press; 2012

[55] Christakou A, Brammer M, Rubia K. Maturation of limbic corticostriatal activation and connectivity associated with developmental changes in temporal discounting. Neuroimage 2011; 54(2) 1344-1354.

[56] Burke A, Austin, T-L. Early identification of Borderline Personality Disorder: A study of abused adolescent girls. Social Worker Practitioner-Researcher 2010; 22 (3) 381-401.

[57] Pincus JH, Tucker GJ. Behavioral Neurology (4 ${ }^{\text {th }}$ ed.). Oxford: Oxford University Press; 2002.

[58] Bandelow B, Schmahl C, Falkai P, Wedekind D. Borderline personality disorder: A dysregulation of the endogenous opioid system? Psychological Review 2010; 117(2), 623-636.

[59] Whitley BE. Principles of research in behavioural sciences (2 ${ }^{\text {nd }}$ ed.). New York: McGraw-Hill; 2002

[60] McLean A, Dowson J, Toone B, Young S, Bazins E, Robbins TW, Sahakian BJ. Characteristics neurocognitve profile associated with adult attention-deficit/hyperactivity disorder. Psychological Medicine 2004; 34 681-692.

[61] Clarke AR, Barry RJ, Heaven PCL, McCarthy R, Selikowitz M, Byrne MK. EEG coherence in adults with attention-deficit/hyperactivity disorder. International Journal of Psychophysiology 2008; 67, 35-40.

[62] Quinn CA. Detection of malingering in assessment of adult ADHD. Archives of Clinical Neuropsychology 2003; 18 379-395. 
[63] Millon T. Millon Clinical Miltiaxial Inventory -III. Minneapolis: Computer Systems Inc.; 1994.

[64] Bates B. Worried Adults May Err in ADHD Self-Diagnosis. Clinical Psychiatry News 1999, 27(4) 24.

[65] Wender PH, Wolf, LE, Wasserstein J. Adults with ADHD. Annals New York Academy of Sciences 2001; 931 1-16.

[66] Goodman DW. ADHD in adults: Update for clinicians on diagnosis and assessment. Primary Psychiatry 2009; 16(11) 38-47.

[67] Kessler RC, Adler L, Ames M, Barkley RA, Birnbaum HG, Greenberg, PE, Johnston JA, Spencer T, Ustun TB. The world health organisation adult ADHD self-report scale (ASRS): A short screening scale for use in the general population. Psychological Medicine 2005; 35(2) 245-256.

[68] Garnier-Dykstra LM, Pinchevsky GM, Caldeira, KM, Vincent KB, Arria, AM. Self-reported adult attention-deficit/hyperactivity disorder symptoms among college students. Journal of American College Health 2010; 59(2) 133-136.

[69] Taylor A, Deb S, Unwin G. Scales for the identification of adults with attention deficit hyperactivity disorder (ADHD): A systematic review. Research in Developmental Disabilities 2011; 32 924-938.

[70] Adler LA, Ciranni M, Shaw DM, Paunikar P. ADHD screening and follow-up: Results from a survey of participants 2 years after and adult ADHD screening day. Primary Psychiatry 2010; 17(2) 32-37.

[71] Groth-Marnat G. Handbook of psychological assessment (3 $3^{\text {rd }}$ ed.). New York: John Wiley \& Sons; 1997.

[72] Craig RJ. New directions in interpreting the Millon Clinical Multi-axial Inventory-III (MCMI-III). New Jersey: John Wiley \& Sons; 2005.

[73] Millon T, Millon C, Davis R, Grossman S. MCMI-III Manual (4 ${ }^{\text {th }}$ Ed.). Minneapolis, MN: Pearson Education; 2009.

[74] Voeller KKS. Attention-deficit hyperactivity disorder (ADHD). Journal of Child Neurology 2004;19 798- 814 .

[75] Kropotov JD. Quantitative EEG, event-related potentials and neurotherapy. London: Academic Press; 2009.

[76] Loo KS, Barkley RA. Clinical utility of EEG in attention deficit hyperactivity disorder. Applied Neuropsychology 2005: 12(2) 64-76.

[77] Biopac MP Systems Hardware [Apparatus and Software]. California, USA: SR Research; 2008.

[78] Zillmer, EA, Spiers, MV, Culbertson, WC. Principles of neuropsychology (2nd ed.). California: Thomason Wadsworth; 2008. 
[79] Pivik RT, Broughton, RJ, Coppola R, Davidson RJ, Fox N, Nuwer MR. Guidelines for the recording and quantitative analysis of electroencephalographic activity in research contexts. Psychophysiology 1993; 30 547-558.

[80] Corsi-Cabrera M, Galindo-Vilchis L, Del-Rio-Portilla Y, Arce C, Ramos-Loyo J. Within-subject reliability and inter-session stability of EEG power and coherent activity in women evaluated monthly over nine months. Clinical Neurophysiology 2007; 118 9-21.

[81] Lansbergen MM, Schutter DJLG, Kenemans JL. Subjective impulsivity and baseline EEG in relation to stopping performance. Brain Research 2007; 1148 161-169.

[82] Dressler O, Schneider G, Stockmanns G, Kochs EF. Awareness and the EEG power spectrum: analysis of frequencies. British Journal of Anaesthetics 2004; 93(6) 806-9.

[83] Campbell IG, Feinberg I. Longitudinal trajectories of non-rapid eye movement delta and theta EEG as indicators of adolescent brain maturation. Proceedings of the National Academy of Science of the United States of America 2009; 106, 5177-5180.

[84] Kurth S, Ringli M, Geiger A, LeBourgeois M, Jenni OG, Huber R. Mapping of cortical activity in the first two decades of life: A high-density sleep electroencephalogram study. The Journal of Neuroscience 2010; 30(40) 13211-13219.

[85] Field A. Discovering statistics using SPSS ( $2^{\text {nd }}$ ed.). London: Sage; 2005.

[86] Fox NA, Hane, AA, Pérez-Edgar K. Psychophysiological methods for the study of developmental psychopathology. In: Cicchetti D, Cohen DJ (Eds.), Developmental psychopathology: Developmental Neuroscience $\left(2^{\text {nd }}\right.$ ed).. New Jersey: John Wiley \& Sons; 2006. p 381-426.

[87] Ringli M, Huber R. Developmental aspects of sleep slow waves: Linking sleep, brain maturation and behaviour. In: Van Someren EJW, Van Der Werf YD, Roelfsema PR, Mansvelder HD, Lopes Da Silva FH(Eds). Progress in brain research: Slow brain oscillations of sleep, resting state and vigilance. London: Elsevier; 2011. p. 63-82 
